\title{
Gravimetrical and surface morphology studies of corrosion inhibition effects of a 4-aminoantipyrine derivative on mild steel in a corrosive solution
}

\author{
M. Hanoon, ${ }^{1}$ D.S. Zinad, ${ }^{2}$ A.M. Resen $^{1}$ and A.A. Al-Amiery ${ }^{2 *}$ \\ ${ }^{1}$ Production engineering and metallurgy, University of Technology, Baghdad 10001, Iraq \\ ${ }^{2}$ Applied Science Department, University of Technology, Baghdad 10001, Iraq \\ *E-mail:100173@uotechnology.edu.iq
}

\begin{abstract}
Corrosion inhibitors are used to protect mild steel surface from corrosive solutions. A corrosion inhibitor is considered as a substance that, when added at a low concentration to acidic or basic environments, will reduce the dissolution of a metal surface. A new corrosion inhibitor derived from antipyrine, namely, 4-((4-(dimethylamino)benzylidene)amino)antipyrine (DBAA), was synthesized and fully characterized by Fourier transform infrared, proton nuclear magnetic resonance and carbon-13 nuclear magnetic resonance spectroscopic techniques and by $\mathrm{CHN}$ micro elemental analysis. The corrosion inhibition efficiency of 4-((4-(dimethylamino)benzylidene)amino)antipyrine in $1 \mathrm{M}$ hydrochloric acid solution on mild steel (MS) surface was investigated using gravimetrical analysis technique. The inhibition efficiency, corrosion rate, mechanism of inhibition and adsorption characteristics were estimated. Scanning electron microscopy (SEM) was used as a second technique to evaluate the new synthesized compound (DBAA) as a corrosion inhibitor. Excellent inhibitive performance for DBAA was determined by gravimetrical analysis. The maximum corrosion inhibition efficiency of $95.1 \%$ was obtained at a concentration of $0.5 \mathrm{mM}$ at $303 \mathrm{~K}$. The inhibition efficiency increases with an increase in the inhibitor concentration but decreases with an increase in the temperature. This study confirms that DBAA obeys the Langmuir adsorption isotherm. A SEM study of the morphology of tested coupons revealed that the surfaces of mild steel coupons were smoother with addition of DBAA in hydrochloric acid environment.
\end{abstract}

Keywords: DBAA, corrosion inhibitor, antipyrine, SEM, adsorption.

Received: April 20, 2020. Published: July 28, 2020

doi: $\underline{10.17675 / 2305-6894-2020-9-3-10}$

\section{Introduction}

Corrosion inhibitors are generally utilized to diminish the attack of an acidic solution that contacts a mild steel surface. Natural and/or organic compounds that comprise heteroatoms, $\pi$-bonds and aromatic rings were usually utilized as corrosion inhibitors for metal surfaces [1]. The significant characteristics of these organic molecules are favored by functional groups containing phosphorous, sulfur, oxygen and nitrogen atoms in their structure [2-5]. Furthermore, most of the organic compounds are costly and toxic. To solve these issues, an 
exhaustive characteristic of newly synthesized, cheap, non-toxic and environmentally friendly inhibitors is important. Inhibitors of this kind can be obtained natural sources. Natural organic compounds are considered as quite significant sources of various organic molecules that can be derived by simple techniques [6]. Recently, various natural resources and synthesized organic compounds were investigated as effective corrosion inhibitors for metals in corrosive solutions [7-19]. The objective of this investigation was to examine the corrosion inhibition of a newly synthesized organic compound DBAA on mild steel coupons in a corrosive solution. The corrosion inhibition attitude of DBAA was tested by weight loss measurements. The mild steel coupon surface protected by various concentrations of DBAA was checked by scanning electron microscopy. Scheme 1 demonstrates the chemical structure of DBAA tested as a corrosion inhibitor.

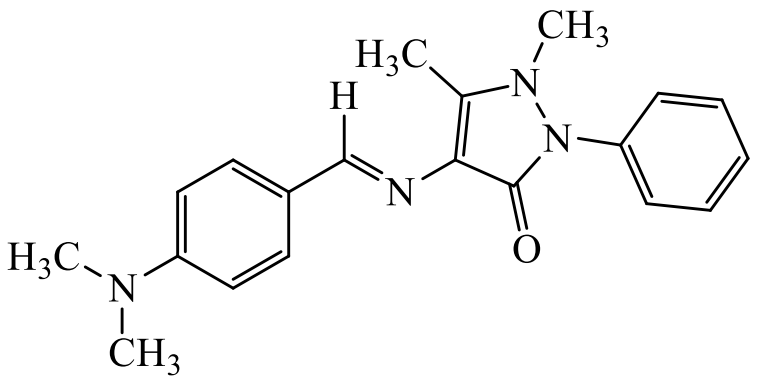

Scheme 1. The chemical structure of DBAA tested as a corrosion inhibitor.

\section{Experimental}

\subsection{Synthesis of $D B A A$}

4-Aminoantipyrine $(10.150 \mathrm{~g}, 50.0 \mathrm{mmol})$ and 4-(dimethylamino)benzaldehyde $(7.450 \mathrm{~g}$, $50.0 \mathrm{mmol})$ in methanol $(70 \mathrm{~mL})$ were stirred at $80^{\circ} \mathrm{C}$. The mixture was refluxed for $18 \mathrm{~h}$ and a few drops of glacial acetic acid were added. The mixture was poured onto ice and the precipitate was filtered off, washed with sodium bisulfate solution, and recrystallized from methanol. The yield was $57.5 \%$, melting point $219.0^{\circ} \mathrm{C}$. The structure of DBAA is demonstrated in Scheme 1. FTIR (Fourier-transform infrared on Thermo Scientific 6700 Nicolate) spectrum of DBAA, $\mathrm{cm}^{-1}: 2943.5$ (aliphatic $-\mathrm{C}-\mathrm{H}$ str), $1591.9(\mathrm{C}=\mathrm{C}), 1641.3$ $(\mathrm{C}=\mathrm{N}), 1666.2(\mathrm{C}=\mathrm{O})$. NMR (Nuclear magnetic resonance on AVANCE III $600 \mathrm{MHz}$ spectrometer): ${ }^{1} \mathrm{H}$ NMR (DMSO-d $\left.{ }_{6}\right)$ ppm: $2.46\left(3 \mathrm{H}, \mathrm{s},=\mathrm{C}-\mathrm{CH}_{3}\right), 2.61\left(6 \mathrm{H}, \mathrm{s},-\mathrm{N}-\mathrm{CH}_{3}\right)$, $3.44\left(3 \mathrm{H}, \mathrm{s},-\mathrm{N}-\mathrm{CH}_{3}\right), 6.83(2 \mathrm{H}, \mathrm{dd}$, aromatic), 7.33-7.38 (1H, t, aromatic), 7.51-7.63 (2H, multiplate, aromatic) and $8.93(1 \mathrm{H}, \mathrm{s}, \mathrm{N}=\mathrm{CH}-) .{ }^{13} \mathrm{C} \mathrm{NMR}$ (DMSO-d ${ }_{6}$ ) ppm: 12.77 $\left(=\mathrm{C}-\mathrm{CH}_{3}\right), 36.58\left(-\mathrm{N}-\mathrm{CH}_{3}\right), 40.70\left(-\mathrm{N}-\mathrm{CH}_{3}\right), 136.83(-\mathrm{C}=\mathrm{C}-\mathrm{N}=), 142.88\left(-\mathrm{C}=\mathrm{C}-\mathrm{CH}_{3}\right)$, $156.39(=\mathrm{C}-\mathrm{CH}=\mathrm{N}-), 166.96(-\mathrm{C}=\mathrm{O}), 134.11$ (aromatic ring, $-\mathrm{C}=\mathrm{C}-$ ), 150.95 (aromatic ring, $-\mathrm{N}-\mathrm{C}=\mathrm{C}-$ ), 110.38 (aromatic ring, $-\mathrm{C}=\mathrm{C}-$ ), 123.88 (aromatic ring, $-\mathrm{C}=\mathrm{C}-$ ), 124.03 (aromatic ring, $-\mathrm{C}=\mathrm{C}-$ ), 129.72 (aromatic ring, $-\mathrm{C}=\mathrm{C}-$ ), 131.44 (aromatic ring, $-\mathrm{C}=\mathrm{C}-$ ), 133.91 (aromatic ring, $-\mathrm{C}=\mathrm{C}-\mathrm{N}$ ). $\mathrm{CHN}$ (Carbon, Hydrogen and Nitrogen analysis on 5500Carlo Erba analyzer) calculated/found: C, 71.83/72.11, H, 6.63/6.88 and N, 16.75/17.02. 


\subsection{Weight loss studies}

Mild steel coupons (Metal Samples Company) with the chemical composition Fe $99.21 \%$, P $0.09 \%$, Si $0.38 \%$, Mn $0.05 \%$, C $0.21 \%$, S 0.05, Al 0.01 were utilized for this study. First of all, each coupon was polished, degreased with acetone, washed with double-distilled water and dried in an oven. A $1 \mathrm{M} \mathrm{HCl}$ solution was prepared from $37 \%$ of $\mathrm{HCl}$ and deionized $\mathrm{H}_{2} \mathrm{O}$. DBAA at concentrations of $0.1 \mathrm{mM}, 0.2 \mathrm{mM}, 0.3 \mathrm{mM}, 0.4 \mathrm{mM}$ and $0.5 \mathrm{mM}$ were tested as the corrosion inhibitor [20-22]. Initially the weighed MS coupons with the dimensions $4.5 \times 4.5 \times 0.5 \mathrm{~cm}^{3}$ were immersed in the corrosive environment for $1,5,10$ and $24 \mathrm{~h}$ in the absence or in the presence of various DBAA concentrations. The measurements were performed in triplicate and were conducted in aerated, non-stirred $1 \mathrm{M} \mathrm{HCl}$. The tested coupons were washed and weighed, and the corrosion rate $\left(C_{R}\right)$ as well as inhibition efficiency (IE\%) were calculated using Equations 1 and 2:

$$
C_{R}=\frac{\Delta W}{a t}
$$

Where $\Delta W$ is the weight change $(\mathrm{mg}), a$ is the mild steel coupon area $\left(\mathrm{cm}^{2}\right)$, and $t$ is the immersion time (h).

$$
\operatorname{IE}(\%)=\frac{W_{1}-W_{\mathrm{i}}}{W_{1}} \cdot 100
$$

Where $W_{1}$ and $W_{\mathrm{i}}$ are the weight change in the absence of a corrosion inhibitor and the weight change in the presence of the corrosion inhibitor in $\mathrm{mg}$, respectively.

\subsection{Surface analysis}

The differences in the coupon surface morphology were tested by a Scanning Electron Microscope (conducted at UKM Electron Microscopy by TM1000 Hitachi Tabletop Microscope). An MS coupon was exposed to the corrosive medium for $5 \mathrm{~h}$ without an inhibitor or at a DBAA concentration of $0.5 \mathrm{mM}[23,24]$. Further, the MS coupons were removed, washed and dried before an SEM study.

\section{Results and Discussion}

\subsection{Chemistry}

In this work, the synthesis of 4-((4-(dimethylamino)benzylidene)amino)antipyrine (DBAA) was accomplished through the reaction of equimolar amounts of 4-aminoantipyrine and 4(dimethylamino)benzaldehyde in methyl alcohol as shown in Scheme 2. The structure of DBAA was confirmed by Fourier-transform infrared (FT-IR) and Nuclear magnetic resonance $\left({ }^{1} \mathrm{H}\right.$ NMR and ${ }^{13} \mathrm{C}$ NMR $)$ spectroscopies and by $\mathrm{CHN}$ analysis technique. The FTIR spectrum recorded for DBAA has peaks that confirm the chemical structure of the compound synthesized. The first absorption peak at $2943.5 \mathrm{~cm}^{-1}$ is assigned to the aliphatic stretching vibration of the methyl group. The peaks at $1591.9,1641.3$ and $1666.2 \mathrm{~cm}^{-1}$ are 
attributed to the stretching vibrations of $\mathrm{C}=\mathrm{C}, \mathrm{C}=\mathrm{N}$ and $\mathrm{C}=\mathrm{O}$ groups, respectively. The ${ }^{1} \mathrm{H}$ NMR spectrum of DBAA has a singlet at $2.46 \mathrm{ppm}$ due to three hydrogen atoms of methyl group bound to vinyl carbon. The second and third important assignments correspond to a singlet at $2.61 \mathrm{ppm}$ for six hydrogen atoms of two methyl groups bound to nitrogen. The last significant methyl group was assigned to the peak at $3.44 \mathrm{ppm}$. The most significant assignment was for singlet proton of the imine group at $8.93 \mathrm{ppm}$. The ${ }^{13} \mathrm{C}$ NMR spectrum has significant assignments at $12.77,36.58$ and $40.70 \mathrm{ppm}$ due to methyl vinyl, N-methyl and N,N-dimethyl groups, respectively. Another significant assignment at $136.83 \mathrm{ppm}$ is due to the carbon atom of the $\mathrm{C}-\mathrm{N}$ group.

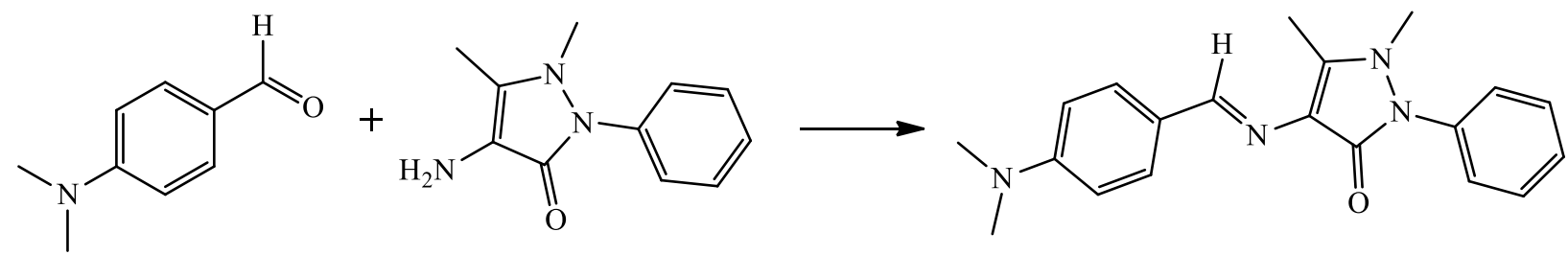

Scheme 2. The reaction of 4-aminoantipyrine and 4-(dimethylamino)benzaldehyde.

\subsection{Weight loss techniques}

The corrosion of MS coupons in $1 \mathrm{M}$ hydrochloric acid solution without and with different concentrations $(0.1-0.5 \mathrm{mM})$ of DBAA was studied at $303 \mathrm{~K}$ by the weight loss techniques for $1,5,10$ and $25 \mathrm{~h}$ immersion times. The corrosion rate (mmpy) and inhibition efficiency (\%) were determined from Equations 1 and 2. Analysis of Figure 1(A) shows that the corrosion rate on the MS surface of the tested coupon without addition of corrosion inhibitor was from 83 to 97 mmpy at various exposure times. The corrosion rate and inhibition efficiency of MS coupons exposed to corrosive solutions at various concentrations of DBAA as corrosion inhibitor for various immersion times $(1,5,10$ and $24 \mathrm{~h})$ are demonstrated in Figure $1(\mathrm{~B}-\mathrm{F})$. The $C_{R}$ (mmpy) for the MS coupon decreased with simultaneous raise in inhibitive efficiency on increasing the DBAA concentration from $0.1 \mathrm{mM}$ to $0.5 \mathrm{mM}$. This achievement indicates an increase in the adsorption of DBAA molecules on the MS coupon surface due to the increase in the DBAA concentration [25-27]. This confirms that DBAA molecules act as an excellent corrosion inhibitor. The inhibition efficiency increased with an increase in DBAA concentration and this suggests that additional DBAA molecules are adsorbed on the coupon surface to form a protective layer.

This behavior can be attributed to an increase in the adsorption area on the coupon surface covered with DBAA molecules that reduce the interaction between the MS surface and the corrosive environment, thereby slowing down the corrosion process. The adsorption of DBAA molecules on the coupon surface is due to the reaction of oxygen/nitrogen unshared electron pairs with the unoccupied d-orbitals of Fe atoms of the coupon surface [28]. The chloride ions of the corrosive environment have an important role in the adsorption mechanism by increasing the coupon surface area due to reactions between the cation and $\mathrm{Cl}$ anion. 

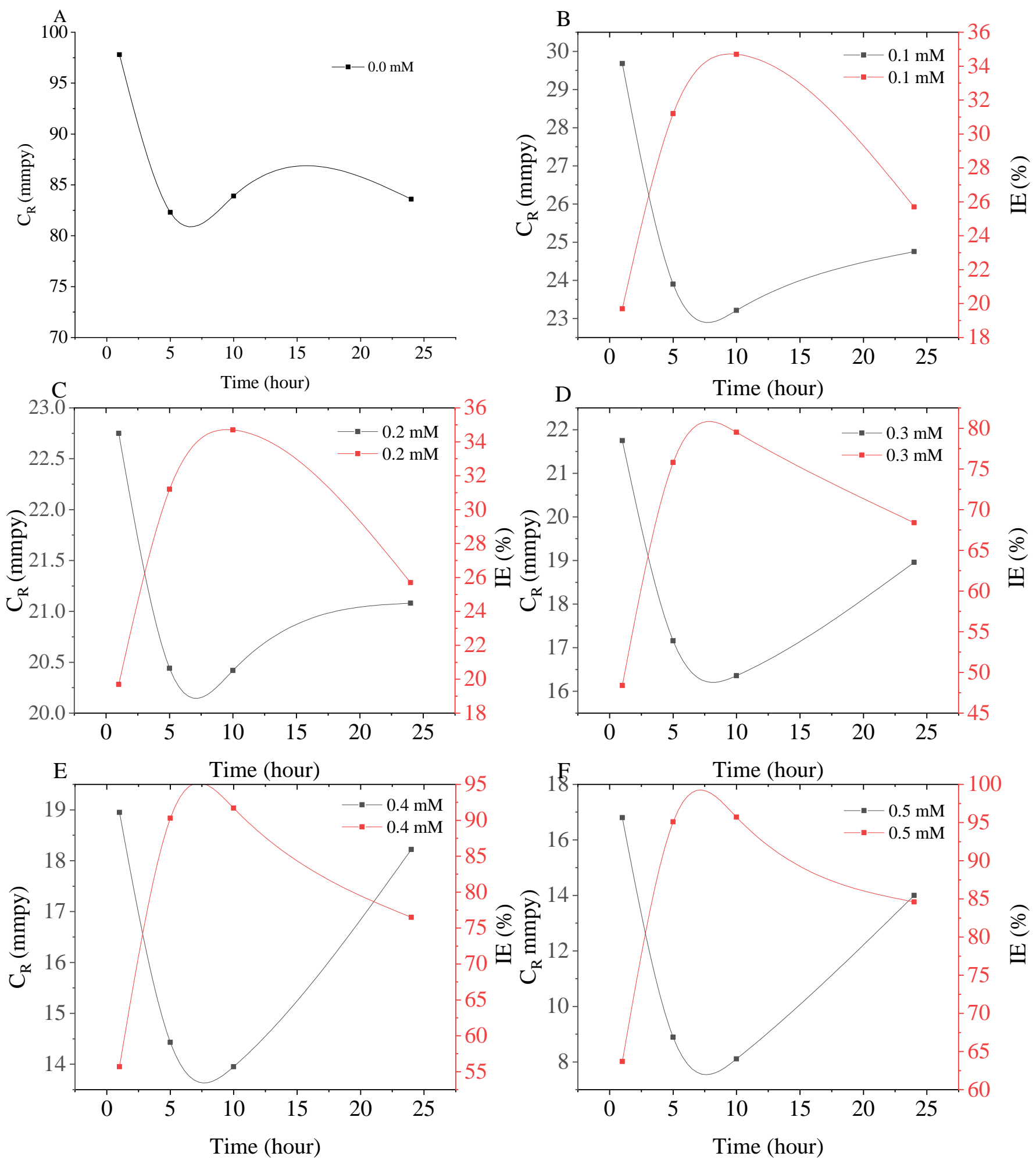

Figure 1. The effect of various concentrations of corrosion inhibitor on the corrosion rate and inhibition efficacy. 


\subsection{Effect of immersion time}

The immersion period is a significant parameter in a study of the inhibition properties of a new corrosion inhibitor. The stability of the adsorption protective layer formed by the new corrosion inhibitor was determined by varying the immersion time. The exposure times were 1, 5, 10 and $24 \mathrm{~h}$. The results are demonstrated in Figure 1, which indicates the impact of the exposure period on the corrosion rates and inhibition efficiency of DBAA. The highest $I E$ was achieved at a small immersion time of $5 \mathrm{~h}$ because of the adsorption of DBAA molecules onto the coupon surface in considerable numbers of DBAA molecules to impede the corrosion of MS in the corrosive solution. The inhibition efficiency was observed to decrease after the longest exposure time that was elected to be $24 \mathrm{~h}$ in this investigation. The reduction in the inhibition efficiency was imputed to the desorption of DBAA molecules from the coupon surface. Furthermore, the corrosion rate increase at a long exposure time due to the dissolution of the coupon surface.

\subsection{Effect of temperature}
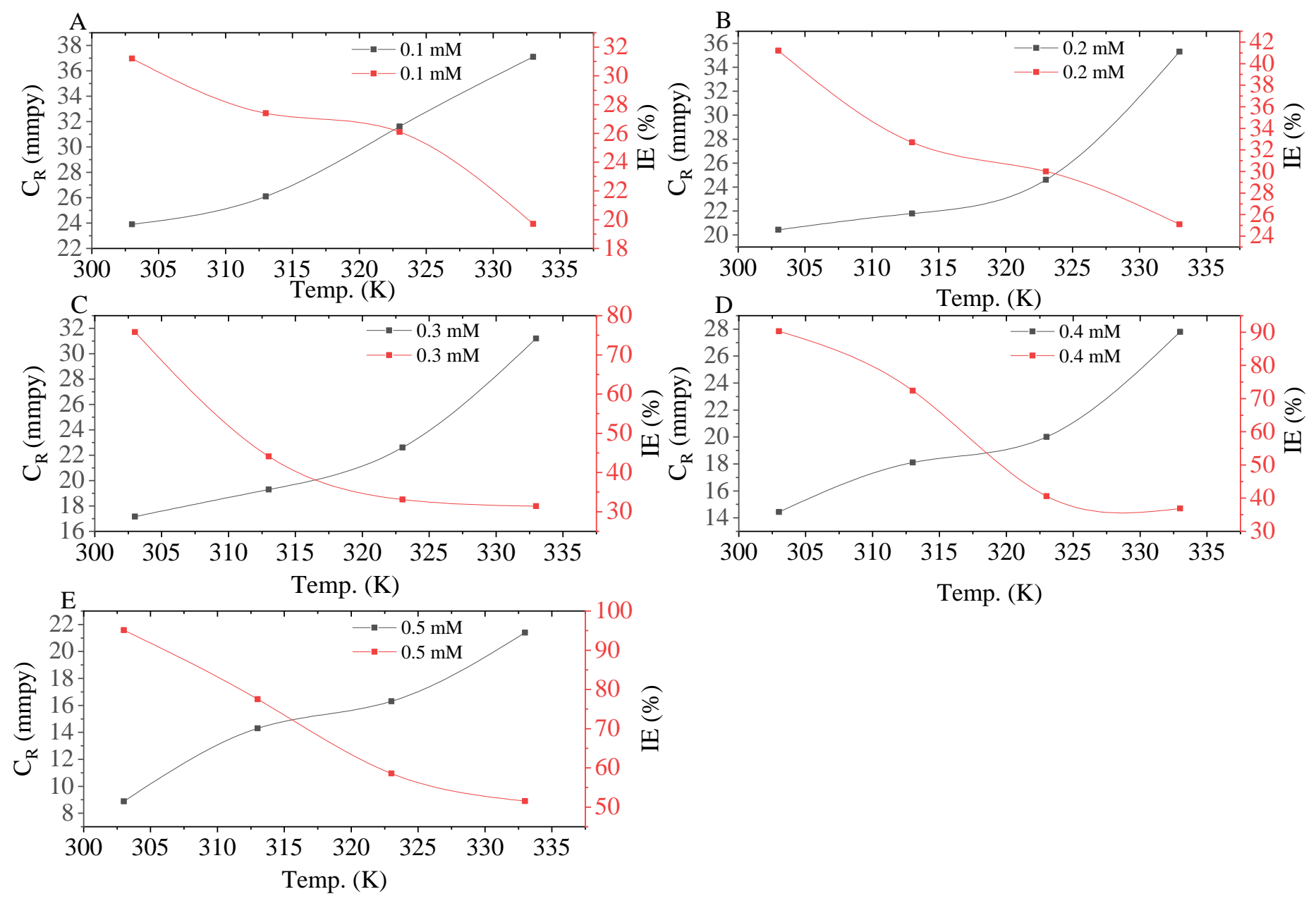

Figure 2. Effect of temperature on the $I E$ of PBSLH in $1 \mathrm{M} \mathrm{HCl}$. 
Gravimetrical techniques were utilized to investigate the effect of temperature on the corrosion of mild steel with addition of DBAA. The results are demonstrated in Figure 2. The results were utilized to determine the $E_{\text {a }}$ (activation energy) of mild steel dissolution and the Gibbs energy of adsorption of DBAA molecules onto the coupon surface. The inhibition efficiency was found to decrease rapidly as the temperature was raised. The inhibition efficiency achieved at the highest tested concentration was $95.1 \%$ at $303 \mathrm{~K}$ and $51.5 \%$ at $333 \mathrm{~K}$ in which the lowest and highest temperatures, respectively, were used in this study. The reduction in inhibition efficiency of DBAA at the studied temperatures $(303,313,323$ and $333 \mathrm{~K}$ ) demonstrated the decomposition of DBAA molecules at higher temperatures. At higher temperatures, DBAA was desorbed from the coupon surface [29-31]. Figure 2 demonstrates the effect of temperature on the corrosion rate and inhibition efficiency.

\subsection{Adsorption isotherms}

The nature of the reaction of the molecules adsorbed on the surface of mild steel with the metal surface can be determined by understanding the isothermal adsorption [32, 33]. The adsorption of DBAA molecules on the MS surface is an essential step in understanding the reaction mechanism. The most imperative factor concerned in this technique is the surface coverage $\theta$ determined from weight loss measurements as displayed by equation (3).

Note: The values of surface coverage $(\theta)$ by an inhibitor were calculated from equation 3, and in essence, they were identified with the degrees of protection [34].

$$
\theta=\frac{W_{1}-W_{\mathrm{i}}}{W_{1}}
$$

Studies of the adsorption isotherms provide the suggested mechanism of the behavior of natural or organic molecules adsorbed on the MS surface. This approach is controlled by several parameters like the surface nature, surface charge, surface electronic properties, solvent, ionic species, solution temperature, and MS/environment interface electrode potential $[35,36]$.

The inhibitor molecules are adsorbed on MS surface when the interaction energy between the MS surface and inhibitor molecules is greater than that of MS surface with $\mathrm{H}_{2} \mathrm{O}$ molecules. In this study, the Frumkin, Temkin and Langmuir adsorption isotherms were examined and the one that showed the best fit was utilized to determine the thermodynamic characteristics. From weight loss measurements, it was concluded that the $I E$ increases upon addition of DBAA to the corrosive environment and this fact was imputed to the formation of a protective layer of DBAA molecules that reduces the dissolution rate on the metal surface. The Langmuir model was used to study the mechanism of adsorption. Equation 4 was utilized to determine the adsorption equilibrium constant.

$$
\frac{C}{\theta}=\frac{1}{K_{\text {ads }}}+B
$$

where $C$ is the DBAA concentration, $K_{\text {ads }}$ is the equilibrium constant, and $B$ is the intercept. 
Figure 3 demonstrates the Langmuir plot that seems to possess a correlation coefficients near unity, which shows that the adsorption of DBAA molecules on the tested coupon surface implies adsorption of one layer. Thus, based on these findings, it was suggested that adsorption of DBAA molecules on the tested coupon surface followed the Langmuir isotherm.

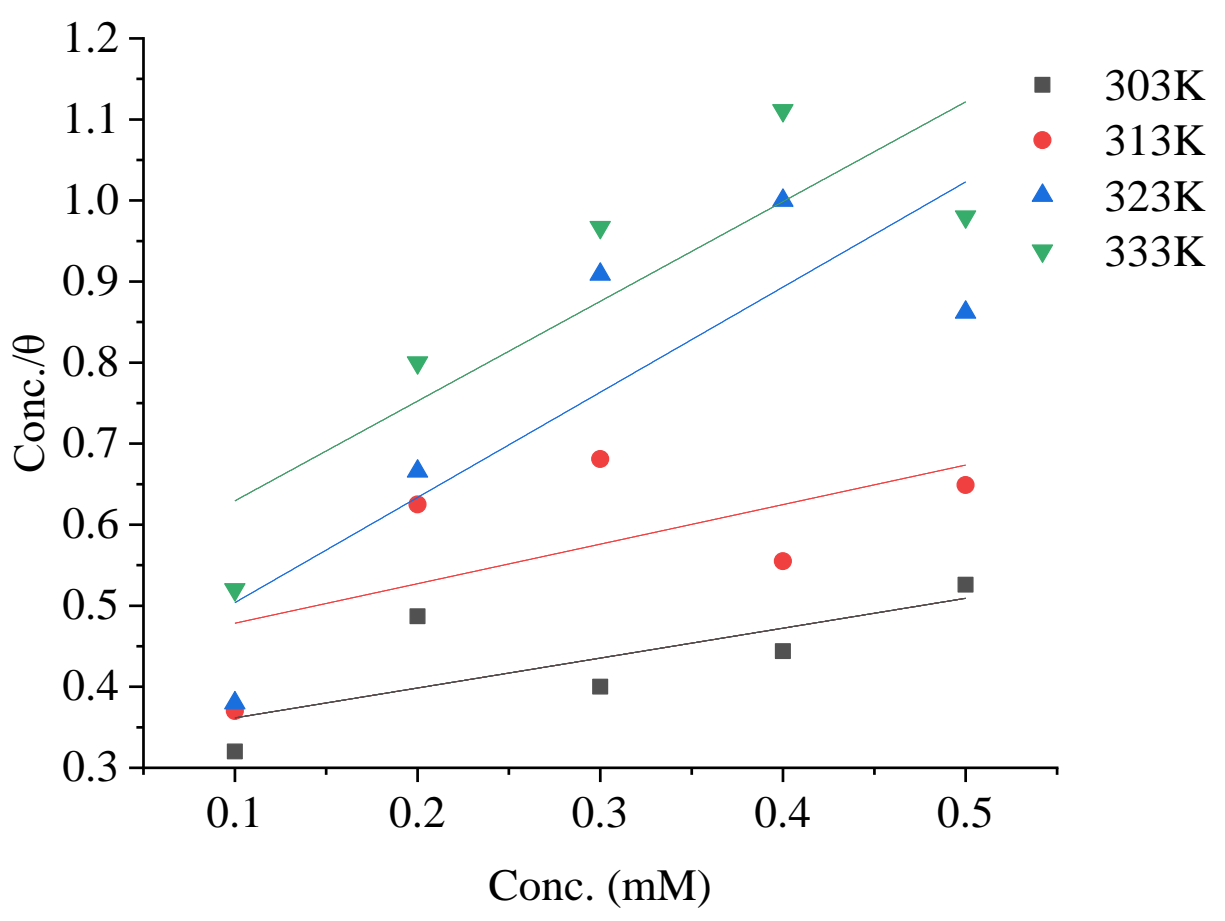

Figure 3. Langmuir adsorption isotherm plot of DBAA molecules.

\subsection{Morphological studies}

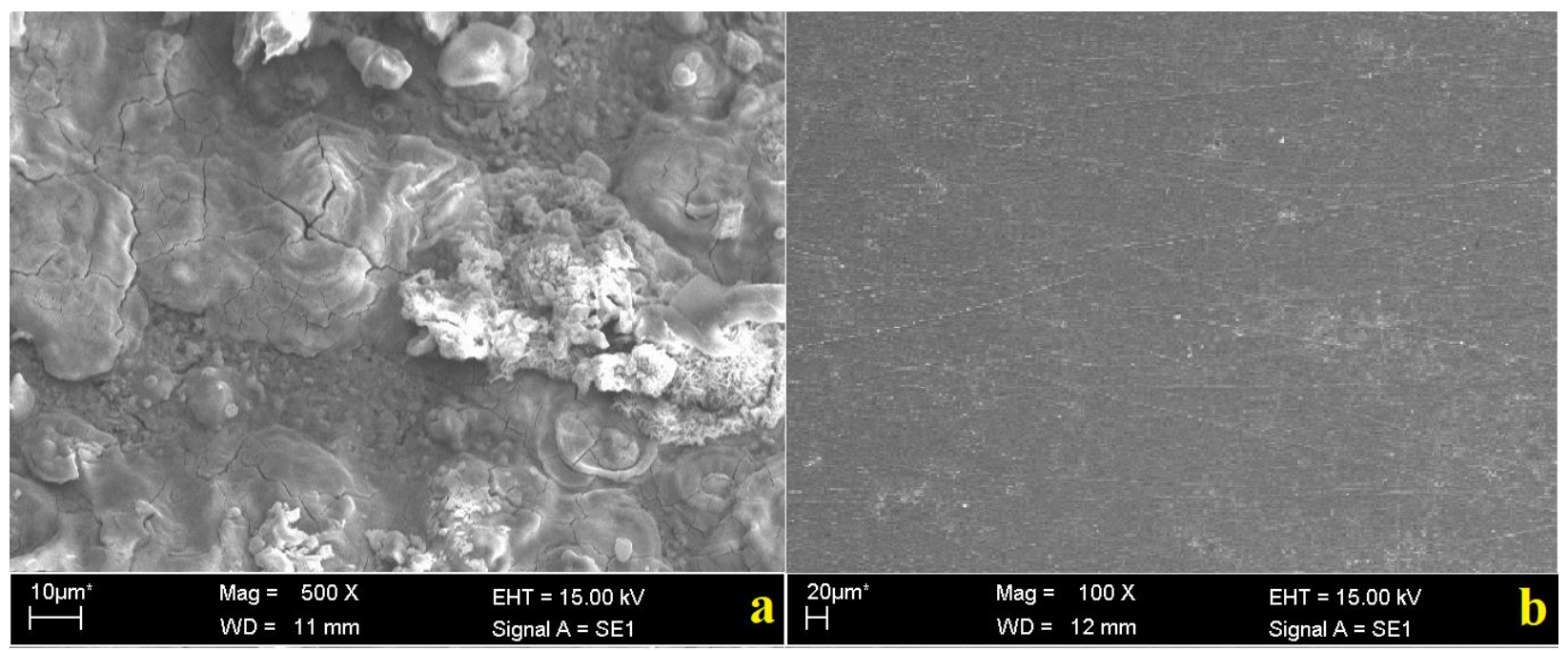

Figure 4. Scanning electron micrographs of tested coupons immersion in $1 \mathrm{M} \mathrm{HCl}$ in the absence (a) and in the presence (b) of 0.5 mM DBAA. 
The scanning electron microscopy (SEM) technique was used to analyze the surface of mild steel without and with addition of DBAA at a concentration of $0.5 \mathrm{mM}$, immersion time $5 \mathrm{~h}$, in $1 \mathrm{M}$ hydrochloric acid environment. Figure 5(a, b) demonstrates the coupon surface micrographs. It can be observed that the coupon surface without DBAA addition was corroded (Figure 4a). On the other hand, Figure $4 \mathrm{~b}$ shows the coupon surface after exposure to the corrosive solution with addition of DBAA. It is obvious from Figure $5 \mathrm{~b}$ that the coupon surface is smooth because DBAA molecules were efficient in decreasing the coupon dissolution. Furthermore, the DBAA molecules that formed a protective layer on the coupon surface reduced the corrosion rate in the corrosive solution.

\subsection{Inhibition mechanism}

Inhibitor adsorption at the coupon interface with the corrosive environment is the initial stage in the inhibiting action mechanism. The inhibition of MS coupons in the $\mathrm{HCl}$ environment by DBAA demonstrates the fact of adsorption [37]. The adsorption mechanism depends on the nature of inhibitor molecules and the nature of the metal surface in addition to the type of the corrosive environment. Recently researchers reported that the adsorption of organic molecules on the mild steel surface generally depends on the physicochemical characteristics of these molecules related to their functional groups and electronic properties in addition to the steric effect of these functional groups.

Moreover, it also depends on the interactions of the inhibitor orbitals with the coupon orbitals that induce strong inhibitor adsorption onto the coupon surface to form a protective layer covering the coupon surface and protecting the surface from the corrosive solution [38-42]. There are three kinds of adsorption, the first one is the electrostatic adsorption that represents the attraction between the charges of inhibitor molecules and mild steel surface. The second one is the interaction of unshared electrons of the inhibitor atoms with the mild steel surface. It is clear that the type of adsorption of DBAA molecules on the mild steel coupon surface depends on the unshared electrons (nitrogen and oxygen heteroatoms), $\pi$-bonds (delocalized electrons) of DBAA molecules, and the unoccupied d-orbitals of atoms on the mild steel surface [43]. The lone pairs of heteroatoms (nitrogen and oxygen) in DBAA molecules are responsible for the adsorption on the coupon surface. The unoccupied d-orbitals of the Fe atoms (Lewis acid) have the ability to accept electrons from inhibitor molecules and form coordination bonds.

In the corrosive environment, organic molecules that have heteroatoms are protonated by the acidic protons and form protonated species that are adsorbed on the mild steel surface (cathodic site) and reduce the hydrogen evolution. The stability of DBAA molecules in the corrosive environment is very important in the inhibition of the mild steel surface from the acidic solution. Nitrogen and oxygen electrons are transferred to the coupon surface and produce a very stable complex through the coordination bonds of DBAA electrons and iron d-orbital. The DBAA molecules have nitrogen and oxygen active adsorption centers that increase the inhibiting effect and excellent corrosion inhibition occurs at the highest concentration used. 
In general, the adsorption of natural/organic molecules could be described based on physisorption and chemisorption. Physisorption is the interaction between the charges of the mild steel surface and the charges of inhibitor molecules, while chemisorption is the reaction between inhibitor molecules through electron pairs and the empty d-orbital of mild steel surface to form a stable coordination complex (Figure 5).

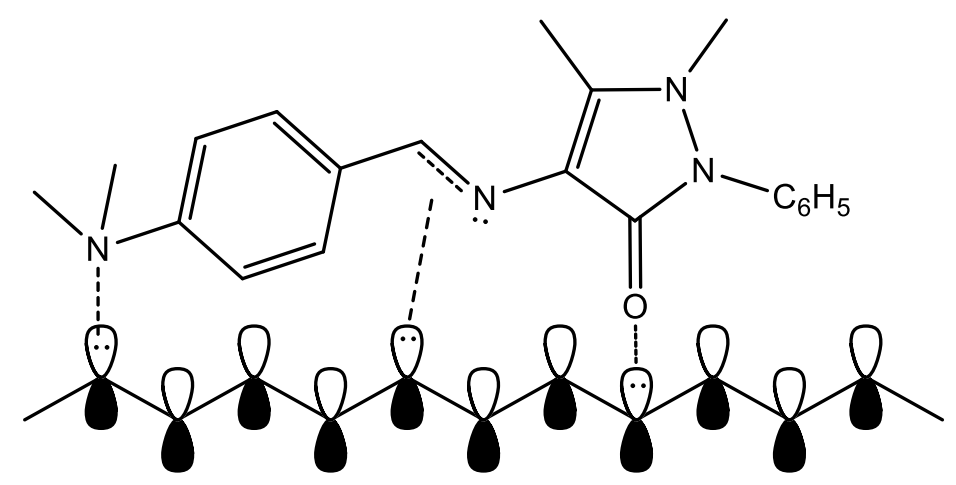

Figure 5. The postulated inhibition mechanism of DBAA.

\section{Conclusions}

The corrosion inhibition of mild steel was investigated by weight loss and morphological techniques. The DBAA molecules reduce the corrosion of the coupon surface in $1 \mathrm{M}$ hydrochloric acid solution to a considerable extent. The inhibitive potency of DBAA molecules is due to the four nitrogen atoms, carbonyl group and aromatic rings which act as adsorption centers. The absorption of DBAA molecules on mild steel surface follows the Langmuir isotherm. SEM confirmed the inhibition by DBAA molecules.

\section{References}

1. N.A. Odewunmi, S.A. Umoren and Z.M. Gasem, Watermelon waste products as green corrosion inhibitors for mild steel in $\mathrm{HCl}$ solution, J. Environ. Chem. Eng., 2015, 3, 286296. doi: $10.1016 /$ j.jece.2014.10.014

2. M. Mobin, R. Aslam and J. Aslam, Non-toxic biodegradable cationic gemini surfactants as novel corrosion inhibitor for mild steel in hydrochloric acid medium and synergistic effect of sodium salicylate: Experimental and theoretical approach, Mater. Chem. Phys., 2017, 191, 151-167. doi: 10.1016/j.matchemphys.2017.01.037

3. G. Moretti, F. Guidi and F. Fabris, Corrosion inhibition of the mild steel in $0.5 \mathrm{M} \mathrm{HCl}$ by 2-butyl-hexahydropyrrolo[1,2-b][1,2]oxazole, Corros. Sci., 2013, 76, 206-218. doi: 10.1016/j.corsci.2013.06.044

4. M. Faustin, A. Maciuk, P. Salvin, C. Roos and M. Lebrini, Corrosion inhibition of C38 steel by alkaloids extract of Geissospermum laeve in $1 \mathrm{M}$ hydrochloric acid: Electrochemical and phytochemical studies, Corros. Sci., 2015, 92, 287-300. doi: $\underline{10.1016 / j . c o r s c i .2014 .12 .005}$ 
5. D.K. Yadav and M.A. Quraishi, Electrochemical investigation of substituted pyranopyrazoles adsorption on mild steel in acid solution, Ind. Eng. Chem. Res., 2012, 51, 8194-8210. doi: $10.1021 / \mathrm{ie} 3002155$

6. G. Achary, H.P. Sachin, Y.A. Naik and T.V. Venkatesha, The corrosion inhibition of mild steel by 3-formyl-8-hydroxy quinoline in hydrochloric acid medium, Mater. Chem. Phys., 2008, 107, 44-50. doi: 10.1016/j.matchemphys.2007.06.038

7. A.A.H. Kadhum, A.B. Mohamad, L.A. Hammed, A.A. Al-Amiery, N.H. San and A.Y. Musa, Inhibition of mild steel corrosion in hydrochloric acid solution by new coumarin, Materials, 2014, 7, no. 6, 4335-4348. doi: $10.3390 / \mathrm{ma} 7064335$

8. A.A. Al-Amiery, A.A.H. Kadhum, A. Kadihum, A.B. Mohamad, C.K. How and S. Junaedi, Inhibition of mild steel corrosion in sulfuric acid solution by new Schiff base, Materials, 2014, 7, no. 2, 787-804. doi: 10.3390/ma7020787

9. A.A. Al-Amiery, A.A.H. Kadhum, A.H.M. Alobaidy, A.B. Mohamad and P.S. Hoon, Novel corrosion inhibitor for mild steel in $\mathrm{HCl}$, Materials, 2014, 7, no. 2, 662-672. doi: 10.3390/ma7020662

10. S.B. Al-Baghdadi, F.G. Hashim, A.Q. Salam, T.K. Abed, T.S. Gaaz, A.A. Al-Amiery, A.A.H. Kadhum, K.S. Reda and W.K. Ahmed, Synthesis and corrosion inhibition application of NATN on mild steel surface in acidic media complemented with DFT studies, Results Phys., 2018, 8, 1178-1184. doi: 10.1016/j.rinp.2018.02.007

11. H.J. Habeeb, H.M. Luaibi, R.M. Dakhil, A.A.H. Kadhum, A.A. Al-Amiery and T.S. Gaaz, Development of new corrosion inhibitor tested on mild steel supported by electrochemical study, Results Phys., 2018, 8, 1260-1267. doi: 10.1016/j.rinp.2018.02.015

12. K.F. Al-Azawi, I.M. Mohammed, S.B. Al-Baghdadi, T.A. Salman, H.A. Issa, A.A. AlAmiery, T.S. Gaaz and A.A.H. Kadhum, Experimental and quantum chemical simulations on the corrosion inhibition of mild steel by 3-((5-(3,5-dinitrophenyl)1,3,4thiadiazol-2-yl)imino)indolin-2-one, Results Phys., 2018, 9, 278-283. doi: 10.1016/j.rinp.2018.02.055

13. A.B. Mohamad, A.A.H. Kadhum, A.A. Al-Amiery, L.C. Ying and A.Y. Musa, Synergistic of a coumarin derivative with potassium iodide on the corrosion inhibition of aluminum alloy in $1.0 \mathrm{M} \mathrm{H}_{2} \mathrm{SO}_{4}$, Met. Mater. Int., 2014, 20, 459-467. doi: 10.1007/s12540-014-3008-3

14. H.R. Obayes, G.H. Alwan, A.H.MJ. Alobaidy, A.A. Al-Amiery, A.A.H. Kadhum and A.B. Mohamad, Quantum chemical assessment of benzimidazole derivatives as corrosion inhibitors, Chem. Cent. J., 2014, 8, 21, 1-8. doi: 10.1186/1752-153X-8-21

15. A.A. Al-Amiery, Y.K. Al-Majedy, A.A.H. Kadhum and A.B. Mohamad, New coumarin derivative as an eco-friendly inhibitor of corrosion of mild steel in acid medium, Molecules, 2015, 20, no. 1, 366-383. doi: 10.3390/molecules20010366

16. E. Yousif, Y.F. Win, A.H. Al-Hamadani, A. Al-Amiery, A.A.H. Kadhum and A.B. Mohamad, Furosemide as an environmental-friendly inhibitor of corrosion of zinc 
metal in acid medium: Experimental and theoretical studies, Int. J. Electrochem. Sci., 2015, 10, 1708-1718.

17. S.B. Al-Baghdadi, F.T.M. Noori, W.K. Ahmed and A.A. Al-Amiery, Thiadiazole as a potential corrosion inhibitor for mild steel in $1 \mathrm{M} \mathrm{HCl}, J$. Adv. Electrochem., 2016, 2 , 67-69.

18. A.A. Al-Amiery, F.A.B. Kassim, A.A.H. Kadhum and A.B. Mohamad, Synthesis and characterization of a novel eco-friendly corrosion inhibition for mild steel in $1 \mathrm{M}$ hydrochloric acid, Sci. Rep., 2016, 6. doi: 10.1038/srep19890

19. A. Kadhim, A.K. Al-Okbi, D.M. Jamil, A. Qussay, A.A. Al-Amiery, T.S. Gaas, A.A.H. Kadhum, A.B. Mohamad and M.H. Nassir, Experimental and theoretical studies of benzoxazines corrosion inhibitors, Results Phys., 2017, 7, 4013-4019. doi: 10.1016/j.rinp.2017.10.027

20. H.R. Obayes, A.A. Al-Amiery, G.H. Alwan, T.A. Abdullah, A.A.H. Kadhum and A.B. Mohamad, Sulphonamides as corrosion inhibitor: experimental and DFT studies, J. Mol. Struct., 2017, 1138, 27-34. doi: $\underline{\text { 10.1016/j.molstruc.2017.02.100 }}$

21. D.M. Jamil, A.K. Al-Okbi, S.B. Al-Baghdadi, A.A. Al-Amiery, A. Kadhim and T.S. Gaaz, Experimental and theoretical studies of Schiff bases as corrosion inhibitors, Chem. Cent. J., 2018, 12, 7, 1-7. doi: 10.1186/s13065-018-0376-7

22. M.H.O. Ahmed, A.A. Al-Amiery, Y.K. Al-Majedy, A.A.H. Kadhum, A.B. Mohamad and T.S. Gaaz, Synthesis and characterization of a novel organic corrosion inhibitor for mild steel in $1 \mathrm{M}$ hydrochloric acid, Results Phys., 2018, 8, 728-733. doi: 10.1016/j.rinp.2017.12.039

23. T.A. Salman, D.S. Zinad, S.H. Jaber, M. Shayaa, A. Mahal, M.S. Takriff and A.A. AlAmiery, Effect of 1,3,4 thiadiazole scafold on the corrosion inhibition of mild steel in acidic medium: an experimental and computational study, J. Bio- Tribo-Corros., 2019, 5, 48, 1-11. doi: $10.1007 /$ s40735-019-0243-7

24. D. Mahmood, A.K. Al-Okbi, M.M. Hanon, K.S. Rida, A.F. Alkaim, A.A. Al-Amiery, A. Kadhum and A.A.H. Kadhum, Carbethoxythiazole corrosion inhibitor: as an experimentally model and DFT theory, J. Eng. Appl. Sci., 2018, 13, 3952-3959. doi: 10.3923/jeasci.2018.3952.3959

25. A.Y.I. Rubaye, K.S. Rida, A.Q. Salam and A. Al-Amiery, Acetamidocoumarin as a based eco-friendly corrosion inhibitor, Int. J. ChemTech Res., 2016, 9, no. 11, 39-47.

26. H.J. Habeeb, H.M. Luaibi, T.A. Abdullah, R.M. Dakhil, A.A.H. Kadhum and A.A. AlAmiery, Case study on thermal impact of novel corrosion inhibitor on mild steel, Case Stud. Therm. Eng., 2018, 12, 64-68. doi: 10.1016/j.csite.2018.03.005

27. S.S. Al-Taweel, K.W.S. Al-Janabi, H.M. Luaibi, A.A. Al-Amiery and T.S. Gaaz, Evaluation and characterization of the symbiotic effect of benzylidene derivative with titanium dioxide nanoparticles on the inhibition of the chemical corrosion of mild steel, Int. J. Corros. Scale Inhib., 2019, 8, no. 4, 1149-1169. doi: 10.17675/2305-6894-2019$\underline{8-4-21}$ 
28. S. Junaedi, A.A.H. Kadhum, A. Al-Amiery, A.B. Mohamad and M.S. Takriff, Synthesis and characterization of novel corrosion inhibitor derived from oleic acid: 2-Amino-5Oleyl 1,3,4-Thiadiazol (AOT), Int. J. Electrochem. Sci., 2012, 7, 3543-3554.

29. D.Q. Zhang, Q.Y. Pan, L.X. Gao and G.D. Zhou, Comparative Study of BisPiperidiniummethyl Urea and Mono-Piperidiniummethyl-Urea as Volatile Corrosion Inhibitors for Mild Steel, Corros. Sci., 2006, 48, 1437-1448. doi: 10.1016/j.corsci.2005.06.007

30. A.A. Al-Amiery, A.A.H. Kadhum, A.B. Mohamad and S. Junaedi, A novel hydrazinecarbothioamide as a potential corrosion inhibitor for mild steel in $\mathrm{HCl}$, Materials, 2013, 6, no. 4, 1420-1431. doi: 10.3390/ma6041420

31. A.A. Al-Amiery, A.A.H. Kadhum, A.B. Mohamad, A.Y. Musa and C.J. Li, Electrochemical study on newly synthesized chlorocurcumin as an inhibitor for mild steel corrosion in hydrochloric acid, Materials, 2013, 6, no. 12, 5466-5477. doi: 10.3390/ma6125466

32. V.S. Sastri and J.R. Perumareddi, Molecular orbital theoretical studies of some organic corrosion inhibitors, Corrosion, 1997, 53, 617-622. doi: 10.5006/1.3290294

33. I. Lukovits, E. Kalman and F. Zucchi, Corrosion inhibitors-correlation between electronic structure and efficiency, Corrosion, 2001, 57, 3-8. doi: 10.5006/1.3290328

34. Yu.I. Kuznetsov, N.N. Andreev and S.S. Vesely, Why we reject papers with calculations of inhibitor adsorption based on data on protective effects, Int. J. Corros. Scale Inhib., 2015, 4, no. 2, 108-109.

35. G. Pearson, Absolute electronegativity and hardness; application to organic chemistry, J. Org. Chem., 1989, 54, 1423-1430. doi: 10.1021/jo00267a034

36. A. Kokalj, On the HSAB based estimate of charge transfer between adsorbates and metal surfaces, Chem. Phys., 2012, 393, 1-12. doi: 10.1016/j.chemphys.2011.10.021

37. A. Al-Amiery, L.M. Shaker, A.H. Kadhum and M.S. Takrif, Synthesis, characterization and gravimetric studies of novel triazole-based compound, Int. J. Low-Carbon Technol., 2020, 15, 164-170. doi: 10.1093/ijlct/ctz067

38. A.E. Stoyanova, G. Petkova and S.D. Peyerimhoff, Correlation between the molecular structure and the corrosion inhibiting effect of some pyrophthalone compounds, Chem. Phys., 2002, 279, 1-6. doi: 10.1016/S0301-0104(02)00408-1

39. O. Benali, L. Larabi, M. Traisnel, L. Gengembre and Y. Harek, Electrochemical, Theoretical and XPS studies of 2-mercapto-1-methylimidazole adsorption on carbon steel in $1 \mathrm{M} \mathrm{HClO}$, Appl. Surf. Sci., 2007, 253, 6130-6139. doi: 10.1016/j.apsusc.2007.01.075

40. J.A.A. Yamin, E. Ali Eh Sheet and A. Al-Amiery, Statistical analysis and optimization of the corrosion inhibition efficiency of a locally made corrosion inhibitor under different operating variables using RSM, Int. J. Corros. Scale Inhib., 2020, 9, no. 2, 502-518. doi: $10.17675 / 2305-6894-2020-9-2-6$ 
41. D.S. Zinad, Q.A. Jawad, M.A.M. Hussain, A. Mahal, L. Mohamed and A.A. AlAmiery, Adsorption, temperature and corrosion inhibition studies of a coumarin derivatives corrosion inhibitor for mild steel in acidic medium: gravimetric and theoretical investigations, Int. J. Corros. Scale Inhib., 2020, 9, no. 1, 134-151. doi: 10.17675/2305-6894-2020-9-1-8

42. D.S. Zinad, M. Hanoon, R.D. Salim, S.I. Ibrahim, A.A. Al-Amiery, M.S. Takriff and A.A.H. Kadhum, A new synthesized coumarin-derived Schiff base as a corrosion inhibitor of mild steel surface in $\mathrm{HCl}$ medium: gravimetric and DFT studies, Int. J. Corros. Scale Inhib., 2020, 9, no. 1, 228-243. doi: 10.17675/2305-6894-2020-9-1-14

43. A. Al-Amiery, T.A. Salman, K.F. Alazawi, L.M. Shaker, A.H. Kadhum and M.S. Takrif, Quantum chemical elucidation on corrosion inhibition efficiency of Schiff base: DFT investigations supported by weight loss and SEM techniques, Int. J. LowCarbon Technol., 2020, 15, 202-209. doi: 10.1093/ijlct/ctz074 